\title{
The 2017 Dutch Physical Activity Guidelines
}

\author{
Rianne M. Weggemans ${ }^{1 *}$, Frank J. G. Backx², Lars Borghouts ${ }^{3}$, Mai Chinapaw ${ }^{4}$, Maria T. E. Hopman ${ }^{5}$
} Annemarie Koster ${ }^{6}$, Stef Kremers ${ }^{7}$, Luc J. C. van Loon ${ }^{6}$, Anne May ${ }^{2}$, Arend Mosterd ${ }^{8}$, Hidde P. van der Ploeg ${ }^{4}$, Tim Takken ${ }^{2}$, Marjolein Visser ${ }^{9}$, G. C. (Wanda) Wendel-Vos ${ }^{10}$, Eco J. C. de Geus ${ }^{9}$ and Committee Dutch Physical Activity Guidelines 2017

\begin{abstract}
Background: The objective of this study was to derive evidence-based physical activity guidelines for the general Dutch population.

Methods: Two systematic reviews were conducted of English language meta-analyses in PubMed summarizing separately randomized controlled trials and prospective cohort studies on the relation between physical activity and sedentary behaviour on the one hand and the risk of all-cause mortality and incidence of 15 major chronic diseases and conditions on the other hand. Other outcome measures were risk factors for cardiovascular disease and type 2 diabetes, physical functioning, and fitness. On the basis of these reviews, an expert committee derived physical activity guidelines. In deriving the guidelines, the committee first selected only experimental and observational prospective findings with a strong level of evidence and then integrated both lines of evidence.

Results: The evidence found for beneficial effects on a large number of the outcome measures was sufficiently strong to draw up guidelines to increase physical activity and reduce sedentary behaviour, respectively. At the same time, the current evidence did not provide a sufficient basis for quantifying how much physical activity is minimally needed to achieve beneficial health effects, or at what amount sedentary behaviour becomes detrimental. A general tenet was that at every level of current activity, further increases in physical activity provide additional health benefits, with relatively larger effects among those who are currently not active or active only at light intensity. Three specific guidelines on (1) moderate- and vigorous-intensity physical activity, (2) bone- and musclestrengthening activities, and (3) sedentary behaviour were formulated separately for adults and children.

Conclusions: There is an unabated need for evidence-based physical activity guidelines that can guide public health policies. Research in which physical activity is measured both objectively (quantity) and subjectively (type and quality) is needed to provide better estimates of the type and actual amount of physical activity required for health.
\end{abstract}

Keywords: Guidelines, Physical activity, Chronic diseases, Fitness, Prospective cohort study, Randomized-controlled trial, Systematic review

\section{Background}

Physical activity and sedentary behaviour guidelines provide guidance on how the general population can improve its health through physical activity. The recommendations in these guidelines are based on a meticulous review of the scientific knowledge available in the international scientific literature. Most existing guidelines are based on evidence from both prospective and cross-sectional

\footnotetext{
* Correspondence: r.weggemans@gr.nl

${ }^{1}$ Health Council of the Netherlands, P.O. Box 16052, 2500, BB, The Hague, The Netherlands

Full list of author information is available at the end of the article
}

studies [1-6]. The aim of the Committee for the Dutch Physical Activity Guidelines 2017 was to derive physical activity guidelines based on the integration of evidence from various kinds of prospective studies, i.e. studies in which physical activity and/or sedentary behaviour was assessed before the outcome was measured. Information from prospective cohort studies (prospective cohort studies, nested case-control studies, and case-cohort studies) was integrated with that of RCTs. These types of studies provide stronger evidence for causality than crosssectional studies [7]. This paper describes the methods of 
derivation, the main results of this effort and a full description of the guidelines [8].

\section{Methods}

A multidisciplinary committee of 14 scientists was appointed, who filled out a declaration of interest published on the website of the Health Council (www. gezondheidsraad.nl). First, a methodology document was prepared, that describes the methods used for the evaluation of the evidence [9]. Based on this methodology the committee supplemented the evidence from existing guidelines with more recently published evidence on the effects of physical activity, endurance and/or strength training and sedentary behaviour on premature mortality risk and the risk of 15 major physical-activity related chronic diseases and other conditions (Table 1). For RCTs the committee also selected cardiometabolic risk factors and fitness indicators as outcomes.

For each outcome measure, the committee used the systematic reviews of the evidence in the most recent guidelines, i.e. the Australian reports [10-12] as a starting point. If the Australian reports did not include any conclusions regarding particular outcome measures, the older report describing the evidence for the US

Table 1 Exposure and outcome measures

\begin{tabular}{ll}
\hline Main exposures: & \\
Physical activity, endurance training, strength training, \\
balance training, sedentary behaviour and TV-watching time \\
Outcome measures: & \\
In prospective cohort studies and RCTs ${ }^{\mathrm{a}}$ & In RCTs \\
Coronary heart disease & Systolic blood pressure \\
Stroke & LDL cholesterol \\
Heart failure & Body weight (adults) and \\
& body mass index (children) \\
Type 2 diabetes mellitus & Insulin sensitivity \\
Chronic obstructive pulmonary diseases & Blood glucose \\
Breast cancer & Fat mass \\
Colorectal cancer & Abdominal fat \\
Lung cancer & Waist circumference \\
Disability & Fat-free mass \\
Fractures & Bone density \\
Osteoarthritis & Cardiorespiratory fitness \\
Musculoskeletal injuries & Functional performance \\
Dementia and cognitive decline & Muscle strength \\
Depression and depressive & \\
symptoms & \\
ADHD symptoms & \\
\hline
\end{tabular}

${ }^{a}$ Meta-analyses of RCTs were encountered only for type 2 diabetes, fractures, musculoskeletal injuries, cognitive decline and depressive symptoms guidelines was additionally used [1]. Next the committee searched the literature for studies on the effects of physical activity and sedentary behaviour published in peerreviewed journals between 2012 up to October 2016 in PubMed, i.e. after publication of the Australian reports. The literature search of the committee for the newer scientific evidence was restricted to pooled analyses, metaanalyses and systematic reviews of RCTs or prospective cohort studies. Only when no pooled/meta-analyses or systematic reviews were available, individual studies were used (for example, RCT regarding the effect of physical activity on the risk of diabetes). In addition, the single cohort study that included objective measurement of physical activity has been described separately, because this measurement is more reliable than the use of self report $[13,14]$.

Systematic reviews and meta-analyses were selected that summarized studies in the general population, with samples spanning the entire lifespan, i.e. from childhood to old age. However, we excluded studies that exclusively used clinical samples or studies in pregnant or lactating women. An exception was made for RCTs in prediabetic, overweight or hypertensive individuals as the prevalence of these conditions in the general population is high.

The committee evaluated the evidence on the health effects of physical activity and sedentary behaviour taking into account the availability of the research, the strength of the associations and the presence of heterogeneity in meta-analysis. We used the decision tree in Additional file 1 when drawing conclusions about the strength of the evidence. On the basis of the experiences of the Health Council with devising a methodology for the 2015 Dutch Dietary Guidelines [15], the committee derived the criteria for the required number of studies and participants for each type of conclusion. The conclusion that the level of evidence is strong or that an effect or association is unlikely implies that there are at least five studies involving 150 participants (RCTs) or 500 cases (cohort studies) with consistent findings; the conclusion that there is a weak level of evidence implies three or four studies and at least 90 participants (RCTs) or 300 cases (cohort studies); one or two studies means that the conclusion is that there is too little research. The required number of participants in individual RCTs naturally depends on the variation in outcome measure and the expected effect size. The experience of the committee is that, albeit arbitrary, these cut-off values are helpful in practice.

Strong evidence from cohort studies and RCTs was then integrated, as next step in the derivation of the guidelines. If the results of cohort studies on chronic diseases and at least one individual RCT with disease as end point were consistent, the committee regarded the support from the evidence as convincing. The committee rated the support 
from the evidence also convincing if the results of the cohort studies and RCTs with a cardiometabolic risk factor were consistent. Finally, a significant effect on a risk factor or indicator of fitness was also rated convincing. If only results of cohort studies were available, the committee judged the association plausible.

In the case of convincing support from both cohort studies and RCTs, the guideline was further quantified by a desirable amount of physical activity. We based these amounts of physical activity or sedentary behaviour on the amounts observed to yield health effects in cohort studies to ensure the attainability of the guidelines in practice. Where possible, quantification was supplemented with data from RCTs regarding the effective levels of intensity, frequency and duration of physical activity. Those conclusions with plausible support only do not provide a sufficient basis to derive quantitative guidelines.

\section{Results}

Most studies relate to the effects in children aged four and older and in adults, whereas data on children up to the age of four years is scarce. The committee provides guidelines for physical activity, muscle- and bonestrengthening physical activity, and for sedentary behaviour separately for children/adolescents from 4 to 18 and for adults. No further subdivision was made between the younger and older adult age span, as no meaningful cut-off age could be found to make such a distinction. The cohort studies in adults that were used for the guidelines often included older persons. For these older persons the evidence in adults can therefore be used with no further modifications. However, a number of additional outcomes were included for older adults: the risk of fractures, disability, and cognitive decline and dementia. The guidelines take this into account, by providing an additional recommendation specifically aimed at older adults.

As indicated in the methods, we used systematic reviews for derivation of the guidelines. In the text below, we use 'cohort studies' and 'RCTs' as a short form for meta-analyses and systematic reviews of cohort studies and RCTs, respectively.

In cohort studies, moderate and high-intensity physical activity is generally compared to no and light-intensity physical activity. In some studies there is no distinction between different intensities, but there is a high amount of physical activity compared to a low amount. In RCTs, usually either endurance or strength training (resistancetype exercise) programmes are studied or a combination of the two.

Physical (in)activity and sedentary behaviour are different kinds of concepts. Physical inactivity refers to an insufficient physical activity level to meet physical activity guidelines. Sedentary behaviour is any waking behaviour characterized by an energy expenditure $\leq 1,5$ metabolic equivalents, while in a sitting, reclining or lying posture [16]. In cohort studies on sedentary behaviour, a high amount of time spent in sedentary behaviour is often compared with a low amount with adjustment for physical activity. Therefore, in studies on physical activity and on sedentary behaviour different comparisons are made.

\section{Adults: health effects of physical activity Physical activity and risk of cardiovascular disease}

There is convincing evidence that physical activity reduces the risk of cardiovascular disease (Table 2) [17]. Cohort research reveals an association between a high level of physical activity and a reduced risk of cardiovascular disease [18-20]. This is supported by RCTs that demonstrate that endurance training and strength training reduce blood pressure [21-23]. In addition, endurance training also reduces fat mass and abdominal circumference [22, 24-26].

The cohort research on cardiovascular disease provides some indication of the required amount and intensity of the physical activity. The key finding is: the more physical activity, the greater the beneficial effects. In relative terms, the greatest benefit can be achieved when a physically inactive person becomes active, i.e. engages in sufficient physical activity of at least moderate intensity: research shows that 75 minutes a week of moderately intensive physical activity reduces the risk of heart attack and heart failure; at 150 minutes a week, the risk decreases further, and at 300 minutes or more the effect is even more beneficial $[18,19]$. The studies on stroke also show a beneficial effect of physical activity of moderate and vigorous intensity [20].

RCTs on cardiovascular outcomes confirm the importance of endurance training of moderate and vigorous intensity and of strength training [21-23]. The typical frequency of the strength training was three to five times a week, using the muscles of the hands or legs four times for two minutes. It was not possible to draw any conclusion regarding the amount of physical activity required based on the RCTs, because the variation between the studies in frequency and duration of the endurance training and the intensity of the strength training was large.

\section{Physical activity and risk of diabetes}

Convincing evidence was found that more physical activity reduces the risk of diabetes [17]. Cohort research shows an association $[27,28]$ that is supported by findings from RCTs. For example, endurance training and strength training have been shown to improve whole body insulin sensitivity $[29,30]$. Endurance training also 
Table 2 Summary of strong evidence for health effects of physical activity and sedentary behaviour

\begin{tabular}{|c|c|c|}
\hline \multicolumn{3}{|c|}{ Health effects of physical activity } \\
\hline Population group & $\begin{array}{l}\text { Cohort research } \\
\text { Physical activity } \\
\text { is associated with } \\
\text { a lower risk of: }\end{array}$ & $\begin{array}{l}\text { RCTs } \\
\text { Physical activity } \\
\text { has a beneficial } \\
\text { effect on: }\end{array}$ \\
\hline \multicolumn{3}{|l|}{ Adults } \\
\hline \multirow[t]{3}{*}{ Convincing } & Depressive symptoms & Depressive symptoms \\
\hline & Cardiovascular disease & $\begin{array}{l}\text { Blood pressure } \\
\text { Fat mass } \\
\text { Abdominal } \\
\text { circumference }\end{array}$ \\
\hline & Diabetes & $\begin{array}{l}\text { Weight } \\
\text { Insulin sensitivity } \\
\text { Diabetes (1 study) }\end{array}$ \\
\hline \multirow[t]{3}{*}{ Plausible } & Breast cancer & \\
\hline & Colorectal cancer & \\
\hline & Premature mortality & \\
\hline \multicolumn{3}{|l|}{ Older adults } \\
\hline \multirow[t]{4}{*}{ Convincing } & \multirow{4}{*}{$\begin{array}{l}\text { Fractures, especially } \\
\text { hip fractures }\end{array}$} & Fractures \\
\hline & & Muscle strength \\
\hline & & Fat-free mass \\
\hline & & Walking speed \\
\hline \multirow[t]{2}{*}{ Plausible } & $\begin{array}{l}\text { Dementia, cognitive decline } \\
\text { and Alzheimer's disease }\end{array}$ & \\
\hline & Disability & \\
\hline \multicolumn{3}{|l|}{ Children } \\
\hline \multirow[t]{6}{*}{ Convincing } & Depressive symptoms & Depressive symptoms \\
\hline & & Cardiorespiratory fitness \\
\hline & & Muscle strength \\
\hline & & Insulin sensitivity \\
\hline & & $\begin{array}{l}\text { Weight and fat mass } \\
\text { in children with } \\
\text { overweight or obesity }\end{array}$ \\
\hline & & Bone quality \\
\hline
\end{tabular}

Health effects of sedentary behaviour
Population group Cohort research Sedentary behaviour is associated with an increased risk of:

Adults

Plausible Death from cardiovascular disease

Premature mortality

reduces body weight in adults with normal weight, excess weight and obesity [1, 22, 24, 25, 31, 32]. Finally, one specifically designed RCT has shown that physical activity reduces the risk of diabetes [33]. How much physical activity is required to reduce the risk of diabetes is not known on the basis of the cohort studies because the amount of physical activity was not quantified sufficiently $[27,28]$. Neither do the RCTs give a good indication. RCTs show that moderate to vigorous-intensity endurance training has a beneficial effect, but the variation in training frequency (three to six times a week) and duration (24 to 90 minutes per session) was too large to determine how much physical activity is needed $[22,24,25,29-32]$. RCTs that examined strength training found favourable effects for two to three training sessions a week at moderate to vigorous intensity. Again, the available data is too limited to determine the minimal or optimal dose for health benefits [29]. In the only RCT examining the effect of physical activity on diabetes, the training programmes used (30 to 60 minutes of light activity per day to five to ten minutes of vigorous-intensity activity per day) differed too widely to quantify the amount of physical activity required [33].

\section{Physical activity and depressive symptoms}

The effect of physical activity on the risk of depressive symptoms is also convincing [17]: cohort research shows an association between physical activity and lower risk of depressive symptoms [1,34]. This is supported by RCTs showing that endurance training at moderate to vigorous intensity and strength training reduce the risk of depressive symptoms [35]. As with diabetes, based on the current evidence, it is not possible to quantify how much physical activity is needed to achieve the beneficial effect.

\section{Premature death, breast cancer and colorectal cancer}

Cohort research has found an association between physical activity and a reduced risk of premature death, breast cancer and colorectal cancer [17, 36-42]. This makes it plausible that there is indeed an association. For premature mortality and breast cancer, there are indications that the greatest relative benefit is achieved when inactive persons (during leisure time) become active. Higher levels of physical activity are associated with further health gains [36-41].

\section{Older adults: fractures, disability and dementia and cognitive decline}

There is convincing evidence that physical activity reduces the risk of fractures in older persons [17]. Cohort studies show that higher levels of physical activity are associated with a lower risk of fractures in general and hip fractures in particular [43, 44], while RCTs demonstrate that the combination of endurance and strength training and/or balance exercises reduce the risk of fractures [45].

The cohort research on fractures does not provide an indication of the amount of physical activity required, as this was insufficiently quantified in the studies [43, 44]. In the RCTs looking at the combination of endurance training and strength training, the endurance training was of moderate to vigorous intensity. However, the 
frequency (one to seven times a week), duration (20 to 60 minutes per session), type of strength training and intensity (light to vigorous) varied too much to make a conclusive statement about the amount required [45].

There is convincing evidence that strength training improves walking speed and muscle strength [17]. There are RCTs that show that strength training increases walking speed in older persons [46, 47]. RCTs also show that strength training increases muscle strength and fatfree mass in older persons [48, 49].

In the RCTs, the beneficial effects on walking speed were found for strength training two to three times a week with 45 to 60 minute sessions [46, 47]. Strength training two to three times a week at light to moderate intensity increases the fat-free mass [48] and the beneficial effect on muscle strength increases with the intensity of strength training $[49,50]$. These studies do not provide data about the number of exercises and the number of times they are performed for each training, and therefore do not provide a basis for a statement about the quantification of physical activity needed to achieve the beneficial effect.

It is plausible that physical activity is associated with a lower risk of disability [17]. Cohort research finds such a link with a moderate to high level of physical activity [51].

As shown by cohort studies $[52,53]$, it is also plausible that higher levels of physical activity in older persons are associated with a lower risk of cognitive decline, dementia and Alzheimer's disease.

\section{Adults: guidelines physical activity Guideline: physical activity is good for you - the more, the better}

A general guideline was derived, in view of the fact that the systematic review of the literature reaffirms the numerous beneficial effects of regular physical activity [Table 2). The key finding is: the more physical activity, the greater the health benefit. Where the recommendations are not attainable, any physical activity is better than none, and this applies to everybody.

Guideline: Engage in physical activity of moderate intensity for at least 150 minutes every week, spread over several days. For example, walking and cycling. The longer you are physically active, and the more frequent and/or more intensive the activity, the more your health will benefit

The committee concludes that research in adults provides grounds for recommending at least 150 minutes of physical activity per week at moderate intensity, spread over several days. A more exact amount of physical activity required for health benefits could not be distilled from the evidence, because in many studies the amount of physical activity was insufficiently quantified. The choice for 150 minutes reflects a deliberate choice for continuity with existing guidelines: we had insufficient grounds to deviate from this widely used amount.

The recommendation to spread the physical activity over several days is predicated on the fact that most RCTs used physical activity programmes that repeat exercises on more than one occasion a week [17]. This gives us confidence that spreading activity over more than one day produces certain benefits, but it does not refute that other schemes could also work. In short, the committee sees no scientific basis for the recommendation to spread the 150 minutes over at least five days a week, nor for recommending continuous bouts of activity that span at least 10 minutes, as required by the current Dutch Norm for Healthy Physical Activity and several other guidelines [2-4, 17, 54-57].

We found convincing evidence that higher amounts of physical activity, in terms of the net product of duration, frequency and/or intensity provide added health benefits, although there appears to be a diminishing gain of extra physical activity at higher levels of one's current physical activity.

\section{Guideline: Engage in activities that strengthen your muscles and bones at least twice a week. Older people should combine these with balance exercises}

As indicated before, the committee has chosen one single guideline for adults and older persons because much adult research includes older persons. The research carried out specifically in older persons confirms the required intensity (moderate to vigorous). Nonetheless, older persons experience additional health gains from specific physical activities targeting balance and strength.

The committee concludes that there is convincing evidence for the benefits of muscle and bone-strengthening exercises in general, and the addition of balance exercises for older persons. Because in most RCTs these exercises were carried out two to three times per week, the committee recommends a frequency of at least twice a week [17]. This corresponds to international physical activity guidelines for muscle-strengthening activities (involving large muscle groups) at least twice a week. Some guidelines also recommend bone-strengthening exercises. Exercises that focus on balance and flexibility are sometimes covered by these guidelines and sometimes under the guidelines for persons with an increased risk of falling [2-4, 56-59].

\section{Adults: health effects of sedentary behaviour}

It is plausible that sedentary behaviour is associated with a higher risk of premature death and death from 
cardiovascular disease [60]. Cohort research shows this association for sedentary behaviour (more than eight hours a day compared to less than four hours a day). This association becomes weaker the more physical activity that people engage in, and is not present in those with a high level of physical activity (significantly more than the norm for physical activity) [61]. The scientific evidence for the health effects of sedentary behaviour is currently much weaker than that for physical activity, both in adults and older persons, and in children (Table 2).

\section{Adults: guideline sedentary behaviour}

\section{Guideline: avoid long periods sitting down}

The research evaluated allows a qualitative recommendation but there is not yet enough data to make a quantitative recommendation. Recent guidelines from Flanders, France, Germany, Australia and Great Britain now advise adults to limit the time that they spend sedentarily. The Flemish guideline recommends interrupting sitting every 30 minutes [59], while the French guideline [62] recommends doing so every 90 to 120 minutes. The variations in international guidelines illustrate that research into the health effects of sedentary behaviour is still emerging $[3,4$, $56,58,59,62]$.

\section{Children and adolescents: health effects of physical activity}

For children most of the (disease) outcomes used for the adults are not yet relevant. However, substantial literature was found for intermediate risk factors, fitness indicators and mental health problems.

\section{Physical activity and depressive symptoms}

There is convincing evidence that physical activity reduces the risk of depressive symptoms [17]. Cohort research finds an association between increased physical activity in children and a lower risk of depressive symptoms $[1,34,63]$ and RCTs show that endurance training in children with an increased risk of these symptoms reduces the chance that these will actually occur [64]. The level of physical activity required for a beneficial effect is not clear. The amount of physical activity was not quantified in cohort studies [1, 34, 63]. The RCTs involved moderate to vigorous intensity endurance training two to three times a week, but the variation in duration (20 to 90 minutes per session) is too large to draw a definitive conclusion on the amount required [64].

\section{BMI, fat mass and insulin sensitivity}

It has been demonstrated convincingly that physical activity reduces body mass index (BMI) and fat mass in children with overweight and obesity, after natural growth is accounted for $[17,65,66]$. No effects have been found in children with a normal weight [67-69].
RCTs have found that endurance training at moderate to vigorous intensities has a beneficial effect on BMI and fat mass in children with overweight and obesity, although these effects are small. The variation in the frequency and duration of the sessions is too large to say how much training is required [11, 64-66].

We also found convincing evidence that strength training during which body weight is used as resistance increases bone quality [17]. However, the required amount of strength training cannot be deduced from these RCTs [70]. The frequency, number of repetitions and duration of physical activity in the studies varied too much, and there was insufficient information about its intensity.

Finally, a combination of endurance and strength training improves insulin sensitivity $[17,71]$. The duration was 40 to 90 minutes, carried out two to four times a week. Because no information is provided about the intensity of training, these RCTs are not sufficient to quantify the amount of training required [71].

\section{Cardiorespiratory fitness and muscle strength}

We found also convincing evidence that endurance training improves cardiorespiratory fitness in children and that strength training increases muscle strength in children [17]. This is evident from RCTs [11, 72, 73]. For an effect on cardiorespiratory fitness, a combination of moderate and vigorous-intensity exercise is required [11]. Here too, the RCTs do not provide any evidence regarding the amount of physical activity required $[11,72,73]$.

\section{Children: physical activity and sedentary behaviour guidelines}

\section{Guideline: Engage in physical activity of moderate intensity for at least one hour every day. The longer you are physically active, and the more frequent and/ or more intensive the activity, the more your health will benefit.}

The often cited beneficial effects of physical activity in children on intermediate risk factors and fitness indicators were fully reaffirmed by our review of the recent literature (Table 2). The research evaluated does not, however, provide enough footing to derive a meaningful quantification for this physical activity. By the same token, it also did not provide grounds for adapting the current norm [17] so we again chose for continuity with existing guidelines. The committee therefore advises children to engage in moderate to high-intensity physical activity for at least one hour every day. This echoes the majority of international guidelines for this age range (at least one hour a day at moderate to vigorous intensity) 
with Germany being the only country to advise at least 90 minutes a day $[2-4,56-59]$.

\section{Guideline: Engage in activities that strengthen your muscles and bones at least three times a week.}

The research evaluated shows the beneficial effects of muscle and bone-strengthening activities. The research allows no conclusions regarding the number of times per week that is required. Neither did the committee find any research into the effects of exercises focusing on flexibility and coordination on risk factors and fitness [17]. Internationally, most countries recommend at least three times a week (as part of the high-intensity physical activity) $[2-4,57-59]$; only the Dutch Norm for Healthy Physical Activity [54,55] mentions twice a week while the German guidelines recommend two to three times a week [56]. The committee has chosen to concur with the majority of the international guidelines for physical activity, at least three times per week, further increasing the coherence of the guidelines across countries.

\section{Guideline: Avoid long periods sitting down.}

The recommendations for sedentary behaviour are entirely based on the adult research described above, neither plausible nor convincing evidence was encountered but this mostly reflects a paucity of research. To err on the side of caution, the committee extends the recommendation for adults to children aged four years and over [60].

\section{Children aged zero to four years}

The committee found no research that provides a basis for establishing a recommendation for this age group [17]. International physical activity guidelines for this age group are based on opinions of experts and experience in practice $[3,4,56,58]$. The Dutch Norm for Healthy Physical Activity includes no separate recommendations for young children [54, 55].

The committee has chosen to make no specific recommendations for this age group. It fully recognizes the importance for young children to engage in varied forms of physical activity to acquire the motor skills that are needed to become physically active after the age of four and onwards [74].

\section{Adverse effects of physical activity}

It is striking that only limited research has been done into the risk of injuries when following a programme aiming to increase the level of physical activity [17]. The committee found weak evidence that a small proportion of people engaging in physical activity may suffer a slight injury, while it is unlikely that increased levels of physical activity increase the risk of serious injuries [75]. However, there are strong indications that the risk of injury is greater for contact sports than non-contact sports $[1,10]$. A large problem in interpreting these 'adverse effects' of sports is that they are not based on the correct comparison of the total injury risk of exercisers and non-exercisers (i.e. injuries inside but also outside the sports and exercise context). The comparison that comes closest to this are the studies comparing effects of physical activity on musculoskeletal health. In these studies the committee found convincing evidence for a protective effect of more physical activity on the incidence of fractures [17, 43-45].

\section{How do the new guidelines relate to the current international and Dutch norms?}

The new guidelines are largely similar to international guidelines and the previous Dutch norms [2-4, 54-59, 76, 77]. However, some differences should be noted (Tables 3 and 4). Compared to the WHO Physical Activity Guidelines

Table 3 The 2017 Dutch, WHO [2] and original Dutch Physical Activity Guidelines [54, 55, 76, 77] for children and adolescents

\begin{tabular}{|c|c|c|}
\hline 2017 Dutch Physical Activity Guidelines & $\begin{array}{l}\text { WHO Global Recommendations on } \\
\text { Physical Activity for Health [2] }\end{array}$ & Original Dutch norms $[54,55,76,77]$ \\
\hline \multicolumn{3}{|l|}{ Physical activity is good for you - the more, the better. } \\
\hline $\begin{array}{l}\text { Engage in physical activity of moderate intensity } \\
\text { for at least one hour every day. The longer you } \\
\text { are physically active, and the more frequent and/ } \\
\text { or more intensive the activity, the more your } \\
\text { health will benefit. }\end{array}$ & $\begin{array}{l}\text { Should do at least } 60 \text { minutes of moderate } \\
\text { to vigorous-intensity physical activity daily. } \\
\text { Physical activity of amounts greater than } \\
60 \text { minutes daily will provide additional } \\
\text { health benefits. }\end{array}$ & $\begin{array}{l}\text { At least one hour per day moderate } \\
\text { to high intensity physical activity } \\
\text { OR } \\
\text { at least three times per week at } \\
\text { least } 20 \text { minutes high intensity physical } \\
\text { activity }\end{array}$ \\
\hline $\begin{array}{l}\text { Do activities that strengthen your muscles } \\
\text { and bones at least three times a week. }\end{array}$ & $\begin{array}{l}\text { Should include activities that strengthen } \\
\text { muscle and bone, at least three times per week. }\end{array}$ & $\begin{array}{l}\text { Of which two times per week activities } \\
\text { focusing on muscle strength, agility, } \\
\text { coordination and bone strength }\end{array}$ \\
\hline And: avoid spending long periods sitting down. & No recommendation & No recommendation \\
\hline $\begin{array}{l}\text { The guidelines do not include a recommendation } \\
\text { on a specific duration of bouts, as there was } \\
\text { insufficient evidence. }\end{array}$ & $\begin{array}{l}\text { In order to be beneficial for cardiorespiratory } \\
\text { health, all activity should be performed in } \\
\text { bouts of at least } 10 \text { minutes duration. }\end{array}$ & $\begin{array}{l}\text { All activity should be performed in } \\
\text { bouts of at least } 10 \text { minutes duration. }\end{array}$ \\
\hline
\end{tabular}


Table 4 The 2017 Dutch, WHO [2] and original Dutch Physical Activity Guidelines [54, 55, 76, 77] for adults and older persons

\begin{tabular}{lll}
\hline 2017 Dutch Physical Activity Guidelines & $\begin{array}{l}\text { WHO Global Recommendations on } \\
\text { Physical Activity for Health [2] }\end{array}$ & Original Dutch norms [54, 55, 76, 77] \\
\hline Adults & Adults 18-65 years & Adults 18-55 years
\end{tabular}

Physical activity is good for you - the more, the better.

Engage in physical activity of moderate intensity for at least 150 minutes every week, spread over several days. For example, walking and cycling. The longer you are physically active, and the more frequent and/or more intensive the activity, the more your health will benefit.

Do activities that strengthen your muscles and bones at least twice a week. Older people should combine these with balance exercises.

And: avoid spending long periods sitting down.

Older adults

Similar to the recommendations for younger adults above.

The guidelines do not include a recommendation on a specific duration of bouts, as there was insufficient evidence.
Should do at least 150 minutes of moderate-intensity physical activity throughout the week, or do at least 75 minutes of vigorous-intensity physical activity throughout the week, or an equivalent combination of moderate- and vigorous-intensity activity. For additional health benefits, adults should increase their moderate-intensity physical activity to 300 minutes per week, or equivalent.

Muscle-strengthening activities should be done involving major muscle groups on 2 or more days a week.

No recommendation

Adults 65+

The above recommendations for younger adults in combination with:

Those with poor mobility should perform physical activity to enhance balance and prevent falls, 3 or more days per week.

In order to be beneficial for cardiorespiratory health all activity should be performed in bouts of at least 10 minutes duration.
At least 5 days per week at least 30 minutes per day moderate intensity physical activity

OR

at least 3 times per week at least 20 minutes per day high intensity physical activity

No recommendation

No recommendation

Adults 55+

The above recommendations for younger adults with lower cut-off values for moderate and high-intensity physical activity

All activity should be performed in bouts of at least 10 minutes duration. for instance, there is no distinction between younger and older adults [2]. The recommendations for moderate and vigorous-intensity activities are combined in the new guidelines for this group and the minimum amount of physical activity required is not expressed per day, but per week, spread over a number of days. For all age categories applies that higher amounts of physical activity, in terms of the net product of duration, frequency and/or intensity provide added health benefits. Finally, the guideline related to sedentary behaviour is new. There are additional differences with the previous Dutch norms $[54,55,76,77]$.

\section{Discussion}

The 2017 Dutch Physical Activity Guidelines provide advice on how much physical activity the population should adopt to achieve health gains. Based on the existing scientific literature, the committee judged the underpinning of the physical activity guidelines 'convincing'; whereas the underpinning of the sedentary behaviour guideline is 'plausible'. Substantial overall public health gains could be obtained if these guidelines were more widely adopted. Analyses by the National Institute of Public Health based on self report show that only $44 \%$ of Dutch adults and older persons currently meet the new physical activity guidelines in that they perform at least 150 minutes per week of physical activity at moderate intensity, spread over a number of days, and engage in muscle and bone-strengthening activities at least two days a week. Not more than slightly over 40 percent of children engage in physical activity at moderate to vigorous intensity an hour every day and in muscle and bonestrengthening activities at least three days a week [78]. In addition, there are many people in the Netherlands who spend a lot of time sedentarily [79].

Despite the convincing substantiation of the general tenet in the physical activity guidelines that "more is better", the data did not provide sufficient information to quantify the actual amount of physical activity that is minimally needed for an effect on any health outcome, or what the optimal amount would be across all outcome measures considered. Definitions and cut-off values for categories of physical activity and sedentary behaviour vary widely across the cohort studies summarized in meta-analyses and systematic reviews on which we relied for the guidelines. To illustrate this point, most studies based on self report only asked about leisuretime physical activity, not about overall physical activity. Hence, the committee considers the data insufficient to determine whether the associations that apply to leisuretime physical activity also apply to other forms of physical activity, such as household work, other forms of work or transport. Also in RCTs the amount of physical activity prescribed varied widely, with the only stable element being that multiple weekly exercise sessions were used in most interventions. However, duration, frequency and intensity varied substantially. Finally, screen time or time spent watching television have often been used as a proxy for sedentary behaviour, whereas the 
formal definition includes any waking activities performed in a sitting, reclining or lying posture, with low energy expenditure ( $\leq 1.5 \mathrm{MET})$, excluding sleep [16].

The varying operationalisations make it difficult to extract minimal or optimal amounts of physical activity and non-sitting time. For this reason, the committee decided to recommend an amount of physical activity that concurs with other international guidelines and to give only a general guideline to reduce sedentary behaviour $[2-4,56-59]$.

The guidelines are used for education purposes in the Netherlands. They are similar for children and adolescents and for younger and older adults, because there was insufficient evidence to differentiate. However, when implementing the guidelines in practice, education messages regarding physical activity should be further tailored to for example specific age groups, socioeconomic groups and groups with different activity levels.

\section{Limitations to our approach}

The aim of this study was to derive physical activity guidelines for the general Dutch population. Our search therefore excluded patient-only samples. There is a growing literature, particularly in cancer and diabetes, showing that 'exercise=medicine' meaning that physical activity can generate health benefits in a variety of patient groups or reduce the negative effects of disease or its treatment $[80,81]$ Although we acknowledge that our recommendations cannot be generalized to each and all patient populations they should be considered meaningful for many specific patient groups.

A second limitation is the exclusive use of published meta-analyses and systematic reviews. No attempt was made to go back to the primary literature and redo the meta-analyses or systematic reviews on the original single cohort studies or RCTs. This would have allowed the committee to select high quality and high powered studies only and/or explore specific amounts of physical activity. Such a major undertaking would not have been compatible with the time frame of the Health Council and its requestor, the Minister of Health. As most of the meta-analyses and systematic reviews that the committee has used followed the IOM, PRISMA, or MOOSE guidelines for meta-analyses and systematic reviews, the committee presumes them of sufficient quality.

By far the largest limitation in deriving the guidelines was that the majority of the included studies are based on self-reported physical activity and sedentary behaviour. These enable to rank subjects, but are inappropriate when it comes to determining the actual amounts of physical activity and sedentary time [13, 14, 82, 83]. The committee would therefore argue for public health organisations to adopt regular population-based monitoring of physical activity using accelerometers in addition to questionnaires [84, 85]. This recommendation also holds for research into the health effects of physical activity and sedentary behaviour, which would greatly benefit from objective monitoring. The committee expects that the ongoing wave of new research in which physical activity is measured both objectively (quantity) and subjectively (type and quality) will provide better estimates of the type and actual amount of physical activity required for health. Future updates of the guidelines are, therefore, considered an important mission for public health authorities.

\section{Conclusions}

Prospective studies provide convincing evidence in support of the 2017 Dutch physical activity guidelines and plausible evidence for the sedentary behaviour guidelines. There is insufficient evidence for quantifying the amount of physical activity required for health effects. Research based on a combination of objectively and subjectively-assessed physical activity and sedentary behaviour is needed for more specific guidelines.

\section{Additional file}

Additional file 1: Decision tree for drawing conclusions on the level of evidence for effects (RCTs) and associations (cohort studies). (PPTX $104 \mathrm{~kb}$ )

\section{Abbreviations}

BMI: Body Mass Index; RCTs: Randomized-Controlled Trials

\section{Acknowledgements}

The working group thanks dr. Peter M. Engelfriet for his help with the text and Eli van der Heide and dr. Frederike Zwenk for their suggestions during the advisory process with respect to policy and Robert Gelinck for his suggestions with respect to implementation.

Funding

Not applicable.

Availability of data and materials

Not applicable

Authors' contributions

This work summarizes an advisory report by the Health Council of the Netherlands. RMW was at the time employed at the Health Council of the Netherlands. The other authors are members of the Dutch Physical Activity Guidelines 2017 Committee and received compensation for meeting attendance and travelling expenses from the Health Council of the Netherlands. RMW drew a first draft of the manuscript, on which all authors provided comments. RMW incorporated these comments in a final draft. All authors read and approved the final manuscript.

Ethics approval and consent to participate

Not applicable

Consent for publication

Not applicable

Competing interests

FJGB, LB, MC,MTEH, AK, SK, LJCVL, AMa, AMo, HPvdP, TT, MV, GCWWV, EJCdG received compensation for meeting attendance and travelling expenses from the Health Council of the Netherlands. 
LB, SK, LVL, AMa, AMo, TT, MV, GCWWW, EJCdG declare they have no other competing interests. FJGB was share holder of MyDailyLifestyle, was consultant for Nea, producer of ankle braces, and received a research grant from Fonds NutsOhra. MC received research grants from Fonds NutsOhra and The Netherlands Organisation for Health Research and Development; MTHE received research grants from Rousselot and Friesland Campina, outside the submitted work. AK acted as a knowledge partner for the Dutch Diabetes Fund (unpaid). HPvdP participated in EC-FP7 EuroFIT-project, in which PALtechnologies acted as a consortium partner; HPvdP has received research funding from AstraZeneca and Achmea; and Ergotron provided $60 \%$ of sit-stand workstations for free in a research study HPvdP is involved in.

RMW declares she has no competing interests.

\section{Publisher's Note}

Springer Nature remains neutral with regard to jurisdictional claims in published maps and institutional affiliations.

\begin{abstract}
Author details
${ }^{1}$ Health Council of the Netherlands, P.O. Box 16052, 2500, BB, The Hague, The Netherlands. ${ }^{2}$ University Medical Center, Utrecht, the Netherlands. ${ }^{3}$ Fontys University of Applied Sciences, Eindhoven, The Netherlands. ${ }^{4} \mathrm{VU}$ University Medical Center, Amsterdam, The Netherlands. ${ }^{5}$ Radboud University Medical Center, Nijmegen, The Netherlands. 'Maastricht University, Maastricht, The Netherlands. 'Maastricht University Medical Center+, Maastricht, The Netherlands. ${ }^{8}$ Meander Medical Center Amersfoort, Amersfoort, The Netherlands. ${ }^{9}$ Vrije Universiteit Amsterdam and VU University Medical Center, Amsterdam, The Netherlands. ${ }^{10}$ National Institute for Public Health and the Environment, Bilthoven, The Netherlands.
\end{abstract}

Received: 28 November 2017 Accepted: 12 March 2018 Published online: 25 June 2018

\section{References}

1. US Department of Health and Human Services. Physical activity guidelines advisory committee report. 2008. http://www.health.gov/paguidelines/ guidelines/default.aspx\#toc. Accessed 12 Aug 2015.

2. World Health Organisation. Global Recommendations on Physical Activity for Health. Geneva: World Health Organisation; 2010.

3. Canadian Society for Exercise Physiology. Canadian Physical Activity Guidelines and Canadian Sedentary Behaviour Guidelines. 2011. http://www csep.ca/en/guidelines/read-the-guidelines. Accessed 10 Feb 2016

4. Department of Health, Physical Activity, Health Improvement and Protection. Start Active, Stay Active: A report on physical activity from the four home countries' Chief Medical Officers. London: Department of Health, Physical Activity, Health Improvement and Protection; 2011.

5. VIGeZ, Van Acker R, De Meester F. Langdurig zitten: dé uitdaging van de 21ste eeuw. Syntheserapport als actuele onderbouw voor de factsheet sedentair gedrag. Brussel: Vlaams Instituut voor Gezondheidspromotie en Ziektepreventie; 2015.

6. UKK Institute. Reduce sedentary time - get healthier. National recommendations to reduce sedentary time. Helsinki: Ministry of Social Affairs and Health, Finland; 2015. Contract No.: 01-06-2016

7. Grobbee D, Hoes A. Clinical epidemiology. Principles, methods, and applications for clinical research. Sudbury, MA: Jones and Bartlett Publishers, Inc; 2007.

8. Health Council of the Netherlands. Dutch Physical Activity Guidelines 2017. The Hague: Health Council of the Netherlands; 2017. Publication no. 2018/ 08e. https://www.gezondheidsraad.nl/sites/default/files/grpublication/ physical_activity_guidelines_2017_0.pdf. Accessed 15 Nov 2017.

9. Health Council of the Netherlands. Methodology for the evaluation of the evidence. Background document to Dutch physical activity guidelines 2017. The Hague: Health Council of the Netherlands; 2017. Publication no. 2017/ 08Ae. https://www.gezondheidsraad.nl/sites/default/files/grpublication/ background_document_methodology_for_the_evaluation_of_evidence_ 2017.pdf. Accessed 15 Nov 2017.

10. Brown WJ, Bauman AE, Bull FC, Burton NW. Development of evidencebased physical activity recommendations for adults (18-64 years). 2012. http://www.health.gov.au/internet/main/publishing.nsf/Content/healthpubhlth-strateg-phys-act-guidelines/\$File/DEB-PAR-Adults-18-64years.pdf. Accessed 30 Mar 2016.
11. Okely AD, Salmon J, Vella SA, Cliff D, Timperio A, Tremblay MS, et al. Systematic review to update Australian physical activity guidelines for children and young people. Report prepared for the Australian Government Department of Health. 2012. http://www.health.gov.au/internet/main/ publishing.nsf/Content/36ACF52B526AC939CA257DE7001A5D69/\$File/SRAPAGCYP.pdf Accessed 30 Feb 2016.

12. Okely AD, Salmon J, Vella SA, Cliff D, Timperio A, Tremblay MS, et al. A systematic review to inform the Australian sedentary behaviour guidelines for children and young people. Report prepared for the Australian Government Department of Health. 2012. http://www.health.gov.au/ internet/main/publishing.nsf/Content/health-pubhlth-strateg-phys-actguidelines/\$File/SR-ASBGCYP.pdf Accessed 30 Mar 2016

13. Helmerhorst HJ, Brage S, Warren J, Besson H, Ekelund U. A systematic review of reliability and objective criterion-related validity of physical activity questionnaires. Int J Behav Nutr Phys Act. 2012;9:103.

14. Silsbury Z, Goldsmith R, Rushton A. Systematic review of the measurement properties of self-report physical activity questionnaires in healthy adult populations. BMJ open. 2015;5(9):e008430.

15. Health Council of the Netherlands. Dutch dietary guidelines 2015. The Hague: Health Council of the Netherlands; 2015. Publication No. 2015/24E. https://www.gezondheidsraad.nl/sites/default/files/201524edutch_dietary_ guidelines_2015.pdf. Accessed 15 Nov 2017

16. Tremblay MS, Aubert S, Barnes JD, Saunders TJ, Carson V, Latimer-Cheung $A E$, et al. Sedentary Behavior Research Network (SBRN) - Terminology Consensus Project process and outcome. Int J Behav Nutr Phys Act. 2017; 14(1):75.

17. Health Council of the Netherlands. Physical activity and risk of chronic diseases. Background document to Dutch physical activity guidelines 2017. The Hague: Health Council of the Netherlands; 2017. Publication number 2017/08B. https://www.gezondheidsraad.nl/sites/default/files/grpublication/ background_document_physical_activity_and_risk_of_chronic_diseases_0. pdf. Accessed 15 Nov 2017.

18. Sattelmair J, Pertman J, Ding EL, Kohl HW 3rd, Haskell W, Lee IM. Dose response between physical activity and risk of coronary heart disease: a meta-analysis. Circulation. 2011;124(7):789-95.

19. Pandey A, Garg S, Khunger M, Darden D, Ayers C, Kumbhani DJ, et al. DoseResponse Relationship Between Physical Activity and Risk of Heart Failure: A Meta-Analysis. Circulation. 2015;132(19):1786-94.

20. Li J, Siegrist J. Physical activity and risk of cardiovascular disease-a metaanalysis of prospective cohort studies. Int J Environ Res Public Health. 2012; 9(2):391-407.

21. Cornelissen VA, Smart NA. Exercise training for blood pressure: a systematic review and meta-analysis. J Am Heart Assoc. 2013;2(1):e004473.

22. Murtagh EM, Nichols L, Mohammed MA, Holder R, Nevill AM, Murphy MH. The effect of walking on risk factors for cardiovascular disease: an updated systematic review and meta-analysis of randomised control trials. Prev Med. 2015;72:34-43.

23. Inder JD, Carlson DJ, Dieberg G, McFarlane JR, Hess NC, Smart NA. Isometric exercise training for blood pressure management: a systematic review and meta-analysis to optimize benefit. Hypertens Res. 2016;39(2):88-94.

24. Gao HL, Gao HX, Sun FM, Zhang L. Effects of walking on body composition in perimenopausal and postmenopausal women: a systematic review and meta-analysis. Menopause. 2016;23(8):928-34.

25. Hespanhol Junior LC, Pillay JD, van Mechelen W, Verhagen E. Meta-Analyses of the Effects of Habitual Running on Indices of Health in Physically Inactive Adults. Sports Med. 2015;45(10):1455-68.

26. Kuhle CL, Steffen MW, Anderson PJ, Murad MH. Effect of exercise on anthropometric measures and serum lipids in older individuals: a systematic review and meta-analysis. BMJ open. 2014;4(6):e005283.

27. Cloostermans L, Wendel-Vos W, Doornbos G, Howard B, Craig CL, Kivimaki $M$, et al. Independent and combined effects of physical activity and body mass index on the development of Type 2 Diabetes - a meta-analysis of 9 prospective cohort studies. Int J Behav Nutr Phys Act. 2015;12:147.

28. Aune D, Norat T, Leitzmann M, Tonstad S, Vatten LJ. Physical activity and the risk of type 2 diabetes: a systematic review and dose-response metaanalysis. Eur J Epidemiol. 2015;30(7):529-42.

29. Mann S, Beedie C, Balducci S, Zanuso S, Allgrove J, Bertiato F, et al. Changes in insulin sensitivity in response to different modalities of exercise: a review of the evidence. Diabetes Metab Res Rev. 2014;30(4):257-68.

30. Lin X, Zhang X, Guo J, Roberts CK, McKenzie S, Wu WC, et al. Effects of Exercise Training on Cardiorespiratory Fitness and Biomarkers of 
Cardiometabolic Health: A Systematic Review and Meta-Analysis of Randomized Controlled Trials. J Am Heart Assoc. 2015. https://doi.org/ 10.1161/JAHA.115.002014.

31. Weber Buchholz S, Wilbur J, Halloway S, McDevitt JH, Schoeny ME. Physical activity intervention studies and their relationship to body composition in healthy women. In: Kasper CE, Smith BA, editors. Annual review of nursing research Exercise in health and disease. 31. New York: Springer Publishing Company; 2013. p. 71-142.

32. Thorogood A, Mottillo S, Shimony A, Filion KB, Joseph L, Genest J, et al. Isolated aerobic exercise and weight loss: a systematic review and metaanalysis of randomized controlled trials. Am J Med. 2011;124(8):747-55.

33. Pan XR, Li GW, Hu YH, Wang JX, Yang WY, An ZX, et al. Effects of diet and exercise in preventing NIDDM in people with impaired glucose tolerance. The Da Qing IGT and Diabetes Study. Diabetes Care. 1997;20(4):537-44.

34. Mammen G, Faulkner G. Physical activity and the prevention of depression: a systematic review of prospective studies. Am J Prev Med. 2013;45(5):649-57.

35. Rethorst CD, Wipfli BM, Landers DM. The antidepressive effects of exercise: a meta-analysis of randomized trials. Sports Med. 2009;39(6):491-511.

36. Arem H, Moore SC, Patel A, Hartge P, Berrington de Gonzalez A Visvanathan $\mathrm{K}$, et al. Leisure time physical activity and mortality: a detailed pooled analysis of the dose-response relationship. JAMA Intern Med. 2015 175(6):959-67.

37. Ekelund U, Ward HA, Norat T, Luan J, May AM, Weiderpass E, et al. Physical activity and all-cause mortality across levels of overall and abdominal adiposity in European men and women: the European Prospective Investigation into Cancer and Nutrition Study (EPIC). Am J Clin Nutr. 2015; 101(3):613-21.

38. Hupin D, Roche F, Gremeaux V, Chatard JC, Oriol M, Gaspoz JM, et al. Even a low-dose of moderate-to-vigorous physical activity reduces mortality by $22 \%$ in adults aged $>/=60$ years: a systematic review and meta-analysis. $\mathrm{Br} \mathrm{J}$ Sports Med. 2015;49(19):1262-7.

39. Moore SC, Lee IM, Weiderpass E, Campbell PT, Sampson JN, Kitahara CM, et al. Association of Leisure-Time Physical Activity With Risk of 26 Types of Cancer in 1.44 Million Adults. JAMA Intern Med. 2016;176(6):816-25.

40. Wu Y, Zhang D, Kang S. Physical activity and risk of breast cancer: a metaanalysis of prospective studies. Breast Cancer Res Treat. 2013;137(3):869-82.

41. Liu L, Shi Y, Li T, Qin Q, Yin J, Pang S, et al. Leisure time physical activity and cancer risk: evaluation of the WHO's recommendation based on 126 highquality epidemiological studies. Br J Sports Med. 2016;50(6):372-8.

42. Robsahm TE, Aagnes B, Hjartaker A, Langseth H, Bray Fl, Larsen IK. Body mass index, physical activity, and colorectal cancer by anatomical subsites: a systematic review and meta-analysis of cohort studies. Eur J Cancer Prev. 2013;22(6):492-505.

43. Qu X, Zhang X, Zhai Z, Li H, Liu X, Li H, et al. Association between physical activity and risk of fracture. J Bone Miner Res. 2014;29(1):202-11.

44. Rong K, Liu XY, Wu XH, Li XL, Xia QQ, Chen J, et al. Increasing Level of Leisure Physical Activity Could Reduce the Risk of Hip Fracture in Older Women: A Dose-Response Meta-analysis of Prospective Cohort Studies. Medicine (Baltimore). 2016;95(11):e2984.

45. Kemmler W, Haberle L, von Stengel S. Effects of exercise on fracture reduction in older adults: a systematic review and meta-analysis. Osteoporos Int. 2013;24(7):1937-50.

46. Van Abbema R, De Greef M, Craje C, Krijnen W, Hobbelen H, Van Der Schans C. What type, or combination of exercise can improve preferred gait speed in older adults? A meta-analysis. BMC Geriatr. 2015;15:72.

47. Hortobagyi T, Lesinski M, Gabler M, VanSwearingen JM, Malatesta D, Granacher U. Effects of Three Types of Exercise Interventions on Healthy Old Adults' Gait Speed: A Systematic Review and Meta-Analysis. Sports Med. 2015:45(12):1627-43.

48. Peterson MD, Sen A, Gordon PM. Influence of resistance exercise on lean body mass in aging adults: a meta-analysis. Med Sci Sports Exerc. 2011:43(2):249-58

49. Borde R, Hortobagyi T, Granacher U. Dose-Response Relationships of Resistance Training in Healthy Old Adults: A Systematic Review and Meta-Analysis. Sports Med. 2015;45(12):1693-720

50. de Labra C, Guimaraes-Pinheiro C, Maseda A, Lorenzo T, Millan-Calenti JC. Effects of physical exercise interventions in frail older adults: a systematic review of randomized controlled trials. BMC Geriatr. 2015;15:154

51. Tak E, Kuiper R, Chorus A, Hopman-Rock M. Prevention of onset and progression of basic ADL disability by physical activity in community dwelling older adults: a meta-analysis. Ageing Res Rev. 2013;12(1):329-38.
52. Beckett MW, Ardern Cl, Rotondi MA. A meta-analysis of prospective studies on the role of physical activity and the prevention of Alzheimer's disease in older adults. BMC Geriatr. 2015;15:9.

53. Blondell SJ, Hammersley-Mather R, Veerman JL. Does physical activity prevent cognitive decline and dementia?: A systematic review and metaanalysis of longitudinal studies. BMC Public Health. 2014;14:510.

54. Kemper HGC, Ooijendijk WTM, Stiggelbout M. Consensus over de Nederlandse Norm voor Gezond Bewegen. Tijdschr Soc Gezondheidsz. 2000;78:180-3.

55. Hildebrandt VH, Ooijendijk WTM, Stiggelbout M. Trendrapport bewegen en gezondheid 1998/1999. Lelystad: Koninklijke Vermande; 1999.

56. Pfeifer K, Banzer W, Ferrari N, Fükézi E, Geidl W, Graf C, et al. Recommendations for physical activity. In: Rütten A, Pfeifer K, editors. National recommendations for physical activity and physical activity promotion. Erlangen: FAU University Press; 2016. p. 19-66.

57. US Department of Health. 2008 Physical Activity Guidelines for Americans. 2008. http://www.health.gov/paguidelines/guidelines/default.aspx\#toc. Accessed 12 Aug 2015.

58. Australian Government Department of Health and Ageing. Australia's Physical Activity and Sedentary Behaviour Guidelines. 2014. http://www. health.gov.au/internet/main/publishing.nsf/Content/health-pubhlth-strategphys-act-guidelines. Accessed 12 Aug 2015.

59. Vlaams Insituut voor Gezondheidspromotie en ziektepreventie. Aanbevelingen voor beweging. Brussel: Vlaams Insituut voor Gezondheidspromotie en ziektepreventie; 2016. http://www.vigez.be/themas/voeding-en-beweging/ aanbevelingen/aanbevelingen-voor-beweging. Accessed 26 Apr 2017.

60. Health Council of the Netherlands. Sedentary behaviour and risk of chronic diseases. Background document to Dutch physical activity guidelines 2017. The Hague: Health Council of the Netherlands; 2017. Publication no. 2017/ 08C. https://www.gezondheidsraad.nl/sites/default/files/grpublication/ background_document_sedentary_behaviour_and_risk_of_chronic_ diseases_0.pdf. Accessed 15 Nov 2017.

61. Ekelund U, Steene-Johannessen J, Brown WJ, Fagerland MW, Owen N, Powell KE, et al. Does physical activity attenuate, or even eliminate, the detrimental association of sitting time with mortality? A harmonised metaanalysis of data from more than 1 million men and women. Lancet. 2016; 388(10051):1302-10.

62. French Agency for Food, Environmental and Occupational Health \& Safety. Opinion of the French Agency for Food, Environmental and Occupational Health \& Safety on the "Updating of the PNNS guidelines: Revision of the guidelines relating to physical activity and sedentarity". Maisons-Alfort Cedex: French Agency for Food, Environmental and Occupational Health \& Safety; 2015. ANSES Opinion Request No 2012-SA-0155

63. Bursnall $P$. The relationship between physical activity and depressive symptoms in adolescents: a systematic review. Worldviews Evid Based Nurs. 2014;11(6):376-82.

64. Brown HE, Pearson N, Braithwaite RE, Brown WJ, Biddle SJ. Physical activity interventions and depression in children and adolescents : a systematic review and meta-analysis. Sports Med. 2013;43(3):195-206.

65. Kelley GA, Kelley KS, Pate RR. Effects of exercise on BMI z-score in overweight and obese children and adolescents: a systematic review with meta-analysis. BMC Pediatr. 2014;14:225.

66. Stoner L, Rowlands D, Morrison A, Credeur D, Hamlin M, Gaffney K, et al. Efficacy of Exercise Intervention for Weight Loss in Overweight and Obese Adolescents: Meta-Analysis and Implications. Sports Med. 2016; 46(11):1737-51

67. Mei H, Xiong Y, Xie S, Guo S, Li Y, Guo B, et al. The impact of long-term school-based physical activity interventions on body mass index of primary school children - a meta-analysis of randomized controlled trials. BMC Public Health. 2016;16:205.

68. Cesa CC, Sbruzzi G, Ribeiro RA, Barbiero SM, de Oliveira PR, Eibel B, et al. Physical activity and cardiovascular risk factors in children: meta-analysis of randomized clinical trials. Prev Med. 2014;69:54-62.

69. Guerra PH, Nobre MR, Silveira JA, Taddei JA. The effect of school-based physical activity interventions on body mass index: a meta-analysis of randomized trials. Clinics (Sao Paulo). 2013;68(9):1263-73.

70. Behringer M, Gruetzner S, McCourt M, Mester J. Effects of weight-bearing activities on bone mineral content and density in children and adolescents: a meta-analysis. J Bone Miner Res. 2014;29(2):467-78.

71. Fedewa MV, Gist NH, Evans EM, Dishman RK. Exercise and insulin resistance in youth: a meta-analysis. Pediatrics. 2014;133(1):e163-74. 
72. Lesinski M, Prieske O, Granacher U. Effects and dose-response relationships of resistance training on physical performance in youth athletes: a systematic review and meta-analysis. Br J Sports Med. 2016;50(13):781-95.

73. Behringer M, Vom Heede A, Yue Z, Mester J. Effects of resistance training in children and adolescents: a meta-analysis. Pediatrics. 2010;126(5):e1199-210.

74. Larsen $L R$, Kristensen PL, Junge T, Rexen $C T$, Wedderkopp N. Motor Performance as Predictor of Physical Activity in Children: The CHAMPS Study-DK. Med Sci Sports Exerc. 2015;47(9):1849-56.

75. Girardi A, Babul S, Rajabali F, Pike I. The injury consequences of promoting physical activity: an evidence review. In: A report prepared by the BC Injury Research and Prevention Unit for the Provincial Health Services Authority. Vancouver: BC; 2013.

76. Ministerie van Volksgezondheid, Welzijn en Sport. Nota Tijd voor sport, bewegen, meedoen, presteren. Den Haag; 2005.

77. Ooijendijk WTM, Hildebrandt VH, Hopman-Rock M. Bewegen in Nederland 2000-2005. In: Hildebrandt VH, Ooijendijk WTM, Hopman-Rock M, editors. Trendrapport bewegen en gezondheid 2004/2005. Hoofddorp/Leiden: TNO; 2007.

78. Centraal Bureau voor de Statistiek in samenwerking met Rijksinstituut voor Volksgezondheid en Milieu. Gezondheidsenquête/Leefstijlmonitor. Den Haag; 2016

79. Rijksinstituut voor Volksgezondheid en Milieu. Sport Kernindicatoren. 2017. https://www.volksgezondheidenzorg.info/sport/kernindicatoren/beweeg-enzitgedrag\#!node-beweeggedrag-naar-leeftijd. Accessed 13 Apr 2017.

80. Naci H, loannidis JP. Comparative effectiveness of exercise and drug interventions on mortality outcomes: metaepidemiological study. BMJ. 2013;347:f5577.

81. Stout NL, Baima J, Swisher AK, Winters-Stone KM, Welsh J. A Systematic Review of Exercise Systematic Reviews in the Cancer Literature (2005-2017). PM R. 2017;9(9S2):S347-S84.

82. Lubans DR, Hesketh K, Cliff DP, Barnett LM, Salmon J, Dollman J, et al. A systematic review of the validity and reliability of sedentary behaviour measures used with children and adolescents. Obes Rev. 2011;12(10):781-99.

83. Clark BK, Sugiyama T, Healy GN, Salmon J, Dunstan DW, Owen N. Validity and reliability of measures of television viewing time and other non-occupational sedentary behaviour of adults: a review. Obes Rev. 2009;10(1):7-16.

84. Loyen A, Clarke-Cornwell AM, Anderssen SA, Hagstromer M, Sardinha LB, Sundquist $\mathrm{K}$, et al. Sedentary Time and Physical Activity Surveillance Through Accelerometer Pooling in Four European Countries. Sports Med. 2016;47(7):1421-35.

85. Loyen A, Van Hecke L, Verloigne M, Hendriksen I, Lakerveld J, SteeneJohannessen J, et al. Variation in population levels of physical activity in European adults according to cross-European studies: a systematic literature review within DEDIPAC. Int J Behav Nutr Phys Act. 2016;13:72.

\section{Submit your next manuscript to BioMed Central and we will help you at every step:}

- We accept pre-submission inquiries

- Our selector tool helps you to find the most relevant journal

- We provide round the clock customer support

- Convenient online submission

- Thorough peer review

- Inclusion in PubMed and all major indexing services

- Maximum visibility for your research

Submit your manuscript at www.biomedcentral.com/submit

) Biomed Central 